Дніпровський державний технічний університет, м. Кам'янське

\title{
ФОРМУВАННЯ ПРАКТИЧНИХ НАВИЧОК З ДИСЦИПЛІНИ „ОПТИМІЗАЦІЙНІ МЕТОДИ І МОДЕЛІ” НА ОСНОВІ СУЧАСНИХ ІНФОРМАЦІЙНИХ ТЕХНОЛОГІЙ
}

Вступ. Освітньо-професійні програми підготовки фахівців галузі знань 07 „Управління та адміністрування” передбачають вивчення спеціальної математичної дисципліни „Оптимізаційні методи і моделі”. Основна мета дисципліни полягає в формуванні теоретичних знань та практичних вмінь, що забезпечують обгрунтування управлінських рішень кількісними методами аналізу. Наведена назва сформувалася порівняно недавно, за своїм змістом дисципліна багато в чому перекликається з такими дисциплінами як „Математичне програмування”, „Дослідження операцій”, „Економікоматематичне моделювання" тощо.

Методологічні питання кількісного обгрунтування управлінських рішень досліджувалися в працях багатьох вітчизняних та зарубіжних науковців, які розглядали теоретичні основи та особливості практичної реалізації відповідних методів [1-4]; аналізували проблему в світлі компетентнісного підходу [5]; досліджували можливості використання сучасних інформаційних технологій [6-7]; обговорювали інші аспекти. Аналіз і узагальнення цих праць дозволило запропонувати концепцію підготовки студентів на основі технологічного підходу з переважною орієнтацією на застосування сучасних інформаційних технологій [8]. Реалізація вказаного підходу зумовлює потребу в уточненні змісту та корегуванні акцентів відповідної підготовки з метою забезпечення досягнення глобальної мети - підготовки висококваліфікованих фахівців.

Постановка задачі. Суть технологічного підходу [8] полягає в зведенні до розумного мінімуму теоретичної частини дисципліни і перенесенні основного акценту на технологію вирішення типових задач, включаючи змістовну постановку проблеми; побудову логічної та (або) математичної моделі; методику реалізації моделі за допомогою відповідних програмних засобів; інтерпретацію одержаних результатів. Для деяких типових задач вказані питання досить детально описані в наявній літературі (наприклад, $[1-4,6,7])$, ряд інших розглядається в даному дослідженні.

Результати роботи. Однією $з$ класичних задач математичного програмування $€$ задача про оптимальне використання обмежених ресурсів. Зазвичай вона розглядається як задача лінійного програмування, в якій і цільова функція і всі обмеження подані лінійними функціями. Лінійний характер цільової функції обумовлений тим, що такі показники ефективності, як ціна або прибуток від реалізації одиниці планованої продукції вважаються постійними, незалежними від обсягів випуску. В той же час на практиці ці показники часто залежать від обсягів виробництва або витрат ресурсів, що призводить до нелінійності цільової функції і неможливості розв'язання задачі класичними методами лінійного програмування [2].

Розглянемо задачу про оптимальне використання обмежених ресурсів в наступній постановці.

Нехай деяке підприємство може випускати продукцію трьох видів: $\Pi_{1}, \Pi_{2}, \Pi_{3}$, використовуючи при изьому сировину чотирьох видів: $C_{1}, C_{2}, C_{3}, C_{4}$. Відомі норми 
витрати сировини $і$-го виду на одинищю продукції j-го виду $A_{i j} i$ запаси сировини кожного виду $B_{i}$. Ціна реалізації (а значить, і прибуток) одиниці продукиї залежить від обсягів випуску : $d_{i}=g_{i}\left(x_{1}, x_{2}, x_{3}\right)$.

Необхідно скласти такий план випуску продукиї $\left(x_{1}, x_{2}, x_{3}\right)$, щзоб сумарний прибуток від ї̈ реалізації був найбільшим.

Математична постановка цієї задачі виглядає так: найти такий план випуску продукції $\left(x_{1}, x_{2}, x_{3}\right)$, при якому виконується система обмежень

$$
\left\{\begin{array}{c}
A_{11} x_{1}+A_{12} x_{2}+A_{13} x_{3} \leq B_{1} \\
A_{21} x_{1}+A_{22} x_{2}+A_{23} x_{3} \leq B_{2} \\
A_{31} x_{1}+A_{32} x_{2}+A_{33} x_{3} \leq B_{3} \\
A_{41} x_{1}+A_{42} x_{2}+A_{43} x_{3} \leq B_{3} \\
x_{1} \geq 0, x_{2} \geq 0, x_{3} \geq 0
\end{array}\right.
$$

і забезпечується максимум цільової функції

$$
f\left(x_{1}, x_{2}, x_{3}\right)=d_{1} x_{1}+d_{2} x_{2}+d_{3} x_{3} .
$$

При розв'язанні аналогічної лінійної задачі ( $d_{i}=$ const $)$ традиційно використовується симплексний метод [1-4]. Оскільки його реалізація передбачає не тільки добре знання алгоритму, а й значний обсяг обчислень, останнім часом віддається перевага комп'ютерному розв'язанню задачі в середовищі MS Excel $[3,6,9]$. Покажемо, що даний підхід може бути використаний і у випадку, коли $d_{i}=g_{i}\left(x_{1}, x_{2}, x_{3}\right)$, тобто задача стає нелінійною.

Нехай для кожного виду продукції відома базова норма прибутку $d_{i}^{*}$ i коефіцієнт зміни прибутку в залежності від кількості одиниць випущеної продукції $k_{i}$ так, що $d_{i}=d_{i}^{*} \cdot x_{i}^{k_{i}}$. Тоді цільова функція набуває вигляду

$$
f\left(x_{1}, x_{2}, x_{3}\right)=d_{1}^{*} x_{1}^{k_{1}}+d_{1}^{*} x_{1}^{k_{1}}+d_{1}^{*} x_{1}^{k_{1}}
$$

Для визначеності задамо конкретні значення параметрів даної задачі: $A_{11}=5$, $A_{12}=3, A_{13}=2, A_{21}=3, A_{22}=5, A_{23}=2, A_{31}=1, \quad A_{32}=2, \quad A_{33}=2, A_{41}=4$, $A_{42}=3, \quad A_{43}=1, \quad B_{1}=150, \quad B_{2}=180, B_{3}=128, \quad B_{4}=135, \quad d_{1}^{*}=12, d_{2}^{*}=10$, $d_{3}^{*}=11, k_{1}=0,95, k_{2}=0,97, k_{3}=0,92$.

Оформимо лист робочої книги MS Excel так, як показано на рис.1. При цьому діапазони комірок B2:H3, B4:B11 містять пояснюючий текст. В комірки D4:F9, G4:G7 введені відомі параметри задачі, а в комірки D10:F10 - початковий план випуску продукції. В комірку Н4 введена формула

\section{$=$ СУММПРОИЗВ(D4:F4;\$D\$10:\$F\$10),}

яка потім скопійована в комірки Н5:Н7 (за цими формулами визначаються запаси сировини, необхідні для реалізації пропонованого плану випуску продукції). Комірка Н11 містить формулу обчислення прибутку від реалізації пропонованого плану:

$$
=\mathrm{D} 10^{*} \mathrm{D} 8^{\wedge} \mathrm{D} 9+\mathrm{E} 10^{*} \mathrm{E} 8^{\wedge} \mathrm{E} 9+\mathrm{F} 10^{*} \mathrm{~F} 8^{\wedge} \mathrm{F} 9 .
$$


Зрозуміло, що введений навмання план випуску продукції не є оптимальним, оскільки залишилися невикористаними значні ресурси (рис.1). Скористаємося можливостями стандартного засобу MS Excel Поиск решения для пошуку оптимального плану. Для цього виділимо комірку Н11 і відпрацюємо звичайну процедуру активації вказаного засобу (пункти меню Данные, Поиск решения).

\begin{tabular}{|c|c|c|c|c|c|c|c|c|}
\hline \multicolumn{7}{|c|}{ 삘] Оптимальний розподіл ресурсів [Режим совместимости] } & \multirow{2}{*}{$\begin{array}{c}- \\
\mathrm{H}\end{array}$} & \multirow{2}{*}{$x$} \\
\hline 1 & A & B & $\mathrm{D}$ & $\mathrm{E}$ & $\mathrm{F}$ & G & & \\
\hline 1 & & & & & & & & \\
\hline 2 & & \multirow{2}{*}{$\begin{array}{c}\text { Види } \\
\text { сировини }\end{array}$} & \multicolumn{3}{|c|}{ Види продукції } & Запаси & \multirow{2}{*}{$\begin{array}{l}\text { Потрібно } \\
\text { сировини }\end{array}$} & \\
\hline 3 & & & $\Pi_{1}$ & $\Pi_{2}$ & $\Pi_{3}$ & сировини & & \\
\hline 4 & & $\mathrm{C}_{1}$ & 5 & 3 & 2 & 150 & 100 & \\
\hline 5 & & $\mathrm{C}_{2}$ & 3 & 5 & 2 & 180 & 100 & \\
\hline 6 & & $\mathrm{C}_{3}$ & 1 & 2 & 2 & 128 & 50 & \\
\hline 7 & & $\mathrm{C}_{4}$ & 4 & 3 & 1 & 135 & 80 & \\
\hline 8 & & $\begin{array}{c}\text { Базова норма } \\
\text { прибутку }\end{array}$ & 12 & 15 & 11 & & & \\
\hline 9 & & $\begin{array}{c}\text { Коефіцієнт } \\
\text { зміни } \\
\text { прибутку }\end{array}$ & 0,95 & 0,97 & 0,92 & & & \\
\hline 10 & & $\begin{array}{l}\text { Кількість } \\
\text { одиниць }\end{array}$ & 10,0 & 10,0 & 10,0 & & & \\
\hline 11 & & Прибуток & & & & & $\mathbf{3 3 5 , 0 7}$ & \\
\hline
\end{tabular}

Рисунок 1 - Фрагмент листа MS Excel з початковими даними

Далі заповнимо діалогове вікно Поиск решения: вкажемо цільову комірку \$H\$11 і діапазон змінюваних комірок \$D\$10:\$F\$10; введемо обмеження \$D\$10:\$F\$10>=0 i \$H\$4:\$H $>=\$$ G\$4:\$G7; в полі Равной вкажемо максимальному значению. Для пошуку оптимального плану клацнемо мишкою на кнопці Bыполнить. Лист MS Excel набуде вигляду, показаного на рис.2.

Як видно, в умовах даної задачі прибуток буде найбільшим в разі випуску 1,4 одиниць продукції $\Pi_{1}, 16,4$ одиниць продукції $\Pi_{2}, 46,9$ одиниць продукції П прибутку складе 667,49 гр.од. Сировина видів $\mathrm{C}_{1}, \mathrm{C}_{2}, \mathrm{C}_{3}$ використана повністю; сировина виду $\mathrm{C}_{4}$ ще залишилася.

Зрозуміло, що побудована модель дає можливість розв’язувати таку ж задачу при зміні конкретних значень вихідних даних. Отже, з'являється можливість провести моделювання ситуації. Наприклад, можна з'ясувати, що буде, якщо спробувати:

a) обміняти на сусідньому підприємстві певну кількість сировини $\mathrm{C}_{4}$ (iї забагато, рис.2) на сировину видів $\mathrm{C}_{1}, \mathrm{C}_{2}, \mathrm{C}_{3}$, які вичерпані повністю;

б) підвищити коефіцієнти зміни прибутку;

в) понизити базову норму прибутку певної продукції і т.п. 


\begin{tabular}{|c|c|c|c|c|c|c|c|c|}
\hline \multicolumn{7}{|c|}{ 삘] Оптимальний розподіл ресурсів [Режим совместимости] } & \multirow{3}{*}{ - } & \multirow{2}{*}{$x$} \\
\hline 1 & $\mathrm{~A}$ & $\mathrm{~B}$ & $\mathrm{D}$ & $\mathrm{E}$ & $\mathrm{F}$ & $\mathrm{G}$ & & \\
\hline 1 & & & & & & & & \\
\hline 2 & & \multirow{2}{*}{$\begin{array}{c}\text { Види } \\
\text { сировини }\end{array}$} & \multicolumn{3}{|c|}{ Види продукції } & \multirow{2}{*}{$\begin{array}{c}\text { Запаси } \\
\text { сировини }\end{array}$} & \multirow{2}{*}{$\begin{array}{l}\text { Потрібно } \\
\text { сировини }\end{array}$} & \multirow{2}{*}{+} \\
\hline 3 & & & $\Pi_{1}$ & $\Pi_{2}$ & $\Pi_{3}$ & & & \\
\hline 4 & & $\mathrm{C}_{1}$ & 5 & 3 & 2 & 150 & 150 & \\
\hline 5 & & $\mathrm{C}_{2}$ & 3 & 5 & 2 & 180 & 180 & \\
\hline 6 & & $\mathrm{C}_{3}$ & 1 & 2 & 2 & 128 & 128 & \\
\hline 7 & & $\mathrm{C}_{4}$ & 4 & 3 & 1 & 135 & 101,7 & \\
\hline 8 & & $\begin{array}{c}\text { Базова норма } \\
\text { прибутку }\end{array}$ & 12 & 15 & 11 & & & \\
\hline 9 & & $\begin{array}{c}\text { Коефіцієнт } \\
\text { зміни } \\
\text { прибутку }\end{array}$ & 0,95 & 0,97 & 0,92 & & & \\
\hline 10 & & $\begin{array}{c}\text { Кількість } \\
\text { одиниць }\end{array}$ & 1,4 & 16,4 & 46,9 & & & \\
\hline 11 & & Прибуток & & & & & 667,49 & \\
\hline
\end{tabular}

Рисунок 2 - Фрагмент листа MS Excel з результатами оптимізації

Крім того, можна модифікувати модель, наприклад, вводячи додатково умову цілочисельності розв'язку (продукція являє собою неподільні агрегати).

Ще одним прикладом модифікації базової моделі може бути випадок, коли підприємство вже має наперед проплачене замовлення на виготовлення певної продукції. Отже, його треба виконати неодмінно. Для врахування цього випадку в діалоговому вікні Поиск решения необхідно ввести відповідні умови, наприклад, \$D \$10>=3 (три одиниці першої продукції треба виготовити обов'язково). Можна також дещо змінити цільову функцію, враховуючи фактичний прибуток від вже проданої продукції.

Альтернативним варіантом розв'язання описаної вище задачі на основі сучасних інформаційних технологій є використання системи комп'ютерної математики Math$\mathrm{CAD}[7,9]$. Процедура розв'язання передбачає наявність мінімальних навичок роботи 3 вказаним середовищем, зокрема: вміння записувати арифметичні вирази і описувати функції користувача; розуміння організації обчислювального блоку Given; знайомство зі стандартною функцією Maximize. Фрагмент документа MathCAD з розв'язком обговорюваної задачі наведено на рис.3. Видно, що результат повністю співпадає з одержаним в середовищі MS Excel.

Природно виникає питання: якому з розглянутих програмних засобів слід віддати перевагу при вивченні дисципліни „Оптимізаційні методи і моделі”? Відразу відзначимо, що задача розв'язується в обох випадках значно простіше, ніж при використанні чисельних методів та самостійного програмування на одній з алгоритмічних мов.

Процедура розв'язання в середовищі MS Excel, на наш погляд, більш прозора i зрозуміла майбутнім управлінцям і економістам. Розв'язання задачі ведеться в режимі 


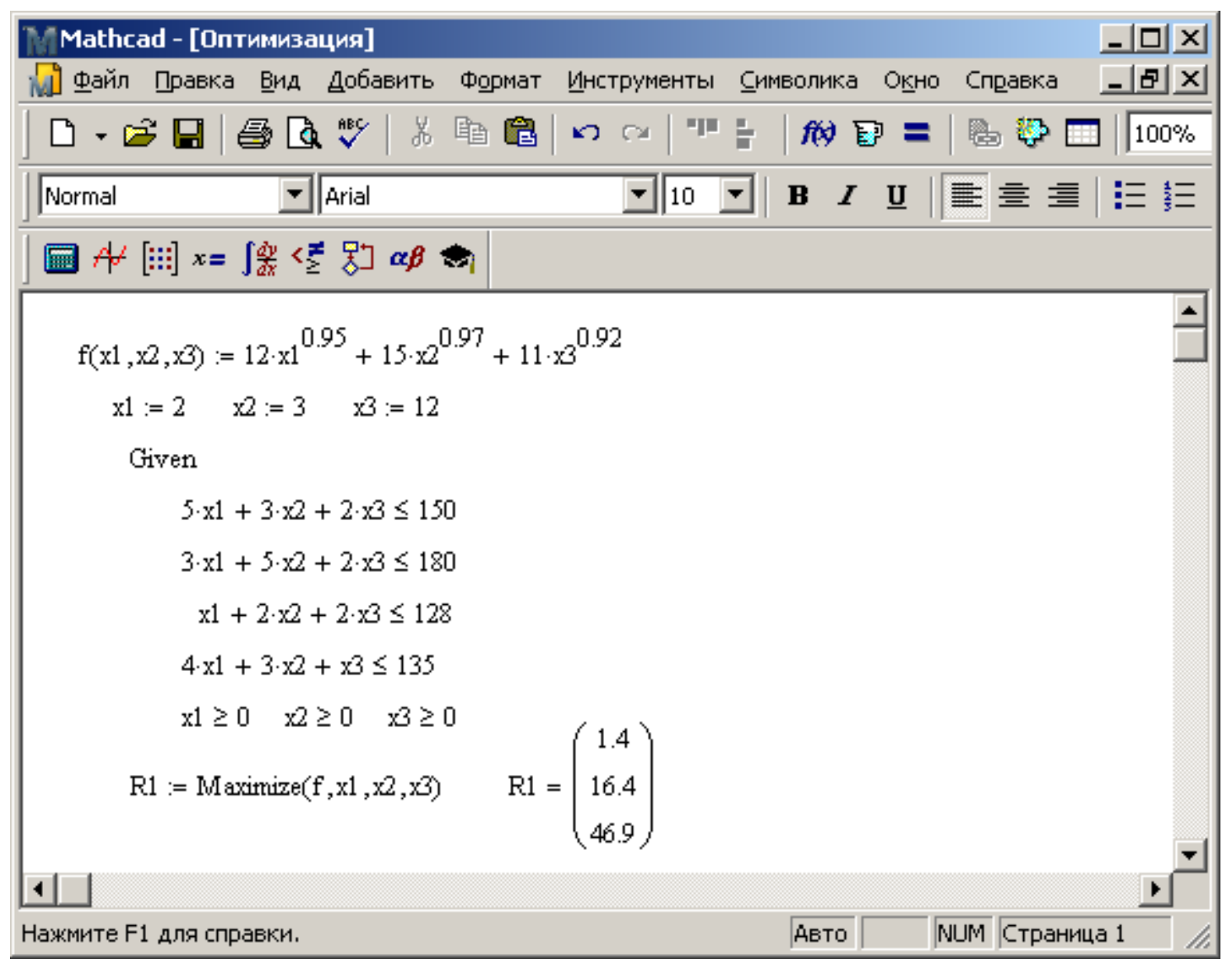

Рисунок 3 - Фрагмент документа MathCAD

маніпулювання даними, процедура побудови початкової таблиці (фактично - опис математичної моделі) наближена до „ручного” розв'язання. Окремі розрахункові дані, необхідні для реалізації процедури оптимізації, можуть бути використані при подальшому аналізі ситуації. Наприклад, дані діапазону комірок Н4:H7 (рис.1, 2) дають можливість оцінити достатність запасів сировини (або невикористані залишки), а дані комірки Н11 - величину прибутку для конкретного плану випуску продукції.

Процедура розв'язання в середовищі МathCAD більш формалізована і звична для користувачів 3 алгоритмічним мисленням та навичками програмування. Вона не така наочна, як в MS Excel. Звичайно, і запаси використаної сировини, і величину прибутку (iх в фрагменті, показаному на рис.3, немає), можна вивести на друк і в середовищі MathCAD. Але для цього потрібно буде ввести додаткові формули і процедури виведення даних.

Зауважимо, що вказані вище докази на користь того чи іншого програмного середовища відступають на другий план перед питанням про готовність студентів до їх використання. Адже навички використання табличних процесорів формуються ще в загальноосвітній школі та на першому курсі університету, закріплюються в процесі вивчення практично всіх дисциплін освітньо-професійних програм підготовки фахівців. Сама програма MS Excel входить до складу популярного пакету Microsoft Office, встановленого практично на кожному комп'ютері. Система комп'ютерної математики MathCAD в загальноосвітній школі, як правило, не вивчається; в базовій підготовці 
економістів і управлінців на першому курсі університету їй також місця зазвичай не знаходиться. До того ж, і на комп'ютерах у більшості користувачів цієї програми немає.

Висновки. Практичні навички 3 дисципліни „Оптимізаційні методи і моделі” можуть бути сформовані на основі систематичного застосування інформаційних технологій. Наведений приклад вирішення нелінійної задачі оптимального використання обмежених ресурсів свідчить про перспективність використання електронних таблиць для формування інформаційної, комп'ютерно-технологічної та процедурно-діяльнісної компетентностей майбутніх фахівців.

\section{ЛІТЕРАТУРА}

1. Таха Хемди А. Введение в исследование операций. Пер. с англ. 6-е издание. М.: Издательский дом "Вильямс", 2001. 912с.

2. Исследование операций в экономике: учеб. пособ. для вузов / Н.Ш.Кремер, Б.А.Путко, И.М.Тришин, М.Н.Фридман; под ред. проф. Н.Ш.Кремера. М.: Банки и биржи, ЮНИТИ, 1997. 407c.

3. Ульянченко О.В. Дослідження операцій в економіці: підручник. Суми: Довкілля, 2010. 594c.

4. Вовк В.М., Зомчак Л.М. Оптимізаційні методи і моделі: навч. посіб. Львів: ЛНУ імені Івана Франка, 2014. 360c.

5. Дутка Г.Я. Проблема формування математичної компетентності у професійній підготовці майбутніх економістів. Вісник Університету банківської справи Національного банку України, 2013. № 2 (17). С.268-272.

6. Кузьмичов А.І. Оптимізаційні методи і моделі: практикум в Excel: навч. посіб. К.: ВПЦ АМУ, 2013. 438c.

7. Математика для экономистов на базе Mathcad / А.А.Черняк, В.А.Новиков, О.И.Мельников, А.В.Кузнецов. СПб.: БХВ-Петербург, 2003. 496с.

8. Карімов I.К., Карімов Г.І. Технологічний підхід до спеціальної математичної підготовки бакалаврів з менеджменту та адміністрування. Математичні проблеми технічної механіки - 2018: всеукр. наук. конф.: тез. доп., мм. Київ, Черкаси, Кам'янське, 16-19 квіт. 2018 р. Кам'янське, 2018. С.85.

9. Карімов І.К. Інформаційно-обчислювальні системи в економіці: навч посіб. 2-ге вид., перероб. і доп. Дніпродзержинськ:ДДТУ, 2013. 279с. 